\title{
Tuberculosis in the third world
}

\section{Size of the problem}

The World Health Organisation estimates that about 1722 million people (one third of the world population) are infected with tubercle bacilli. Furthermore, in 19908 million new cases of tuberculosis occurred, $95 \%$ of them in the developing world and 5\% in industrialised countries. Close to 3 million people die of this disease every year. ${ }^{12}$ These estimates are shown in table 1 for various WHO regions.

The WHO estimates are based on notifications of tuberculosis from different countries. These notifications are incomplete, but this was taken into account in the calculation. The estimates made by the World Bank Group, ${ }^{3}$ based on the calculation of incidence from the risk of infection (table 2), confirm the WHO estimates. The risk of infection was derived from tuberculin surveys in different parts of the world and Styblo's formula, which states that a risk of $1 \%$ is equivalent to an annual incidence of 50 smear positive cases per 100000 population. ${ }^{4}$

All these estimates clearly show that whereas the largest number of cases is in Asia the highest incidence rate is seen in Subsaharan Africa.

\section{PREVALENCE SURVEYS}

In many Asian countries well designed prevalence surveys have been conducted for the past 20-30 years, usually at intervals of five years or so. The findings of three such prevalence surveys, in China, ${ }^{5}$ Korea, ${ }^{6}$ and the Philippines, are shown in table 3 . The rate of bacteriologically confirmed (mainly smear positive) cases is high. This high prevalence reflects not only the high incidence of disease in these countries but also, as will be discussed later, the difficulties encountered with treatment, leading to a large number of chronic cases and relapses.

\section{Determinants of the size of the tuberculosis problem}

Many factors determine the size of the tuberculosis problem. The three main ones, which will be discussed

Table 1 The global toll of tuberculosis

\begin{tabular}{lccc}
\hline Region & $\begin{array}{l}\text { Total } \\
\text { infected } \\
\text { (millions) }\end{array}$ & $\begin{array}{l}\text { New cases } \\
\text { per annum } \\
\text { (thousands) }\end{array}$ & $\begin{array}{l}\text { Deaths } \\
\text { per annum } \\
\text { (thousands) }\end{array}$ \\
\hline Africa & 171 & 1398 & 656 \\
Americas* & 117 & 564 & 220 \\
Eastern Mediterranean & 52 & 594 & 163 \\
South East Asia & 426 & 2480 & 932 \\
Western Pacific† & 574 & 2557 & 894 \\
Industrialised countries & 382 & 409 & 42 \\
Total & 1722 & 8002 & 2907 \\
\hline
\end{tabular}

$\star$ Excluding the United States and Canada.

tExcluding Japan, Australia and New Zealand

$\ddagger$ Australia, Canada, Japan, New Zealand, the United States, and all European countries. here, are: (1) the stage of the epidemic reached within individual countries; (2) the efficacy of the treatment component of the tuberculosis programme; (3) the interrelation between tuberculosis and HIV infection.

\section{Stage of tuberculosis epidemic}

Although certain forms of tuberculosis, or of a disease similar to tuberculosis, are believed to have existed since antiquity, there is sound evidence that the latest epidemic wave of tuberculosis has affected different populations at different times. In Western Europe and in the white population of North America the epidemic achieved its height at the end of the eighteenth and the beginning of the nineteenth century, whereas Eastern Europe was affected some decades later. The large countries of Asia, such as India and China, experienced the height of the epidemic towards the end of the nineteenth century. There is, for instance, good evidence that in the middle of the nineteenth century tuberculosis in India was much more common among British soldiers than Indian soldiers. ${ }^{7}$ The black population of Subsaharan Africa was affected at the beginning of this century, as evidenced by the devastation brought about by the first contact of black troops from Subsaharan Africa with the tubercle bacillus during the first world war in the British and French armies. ${ }^{89}$ The epidemic of tuberculosis probably reaches a peak quite quickly and then shows a steady, slow decline. The rate of this natural decline is probably around $1-2 \%$ a year. The morbidity and mortality due to tuberculosis in a given population depend to a large extent on the stage of the epidemic reached. We are often inclined to ascribe this gradual decline to our own actions, such as the isolation of cases of tuberculosis in the preantimicrobial era and BCG vaccination. The reason for the natural decline is unknown; it may be related to an increase in resistance in a population or to a progressive reduction in the dose of tubercle bacilli acquired in the primary infection.

One of the signs of the stage of the epidemic in a particular population is to be found in the age specific incidence of morbidity or mortality. In the early stages of

Table 2 Estimated annual incidence of all forms of tuberculosis per 100000 population in developing countries (1990)

\begin{tabular}{|c|c|c|c|c|}
\hline \multirow[b]{2}{*}{ Area } & \multicolumn{3}{|c|}{ Estimated No of cases (thousands) } & \multirow{2}{*}{$\begin{array}{l}\text { Incidence } \\
\text { per } 100000\end{array}$} \\
\hline & Low $^{\star}$ & Midpoint* & $H i g h^{\star}$ & \\
\hline Subsaharan Africa & 361 & 635 & 909 & 229 \\
\hline $\begin{array}{l}\text { North Africa and } \\
\text { Western Asia }\end{array}$ & 117 & 323 & 530 & 120 \\
\hline Asia & 2535 & 5102 & 7670 & 174 \\
\hline South America & 129 & 356 & 584 & 120 \\
\hline $\begin{array}{r}\text { Central America } \\
\text { and Caribbean }\end{array}$ & 66 & 185 & 302 & 120 \\
\hline Total & 3503 & 7122 & 10741 & 171 \\
\hline
\end{tabular}

*Based on the confidence interval for the relation between the incidence of disease and the risk of infection. 
Table 3 Prevalence rates of bacteriologically confirmed cases found in prevalence surveys in some Asiatic countries

Rates per 100000 of the population aged over 5 or 10 years

\begin{tabular}{llll}
\hline & Korea & & Philippines \\
1979 & 1975 & 1990 & \begin{tabular}{l}
1981 \\
\cline { 2 - 4 }
\end{tabular} \\
\hline 187 & 760 & 240 & 950 \\
\hline
\end{tabular}

the epidemic tuberculosis affects particularly young adults, whereas during its decline the older age groups show the highest rates. ${ }^{9}$ If we apply this to individual countries, we find that tuberculosis is mainly a disease of young adults in relatively few countries. In most countries it has gradually become a disease of older people. Thus in much of the world today tuberculosis is largely the result of remote infection and in only a few is it mainly the result of recent infection.

\section{Efficacy of the treatment component of the tuberculosis programme}

Chemotherapy, if widely and well applied, can have a tremendous impact on tuberculosis in the community. In developed countries, where tuberculosis was already declining, the introduction of chemotherapy caused an immediate fall in mortality from tuberculosis and a somewhat slower fall in morbidity. The rate of decline, which was around $1-2 \%$ a year before the introduction of chemotherapy, has accelerated to $8-10 \%$ in many developed countries. What has not been realised, until relatively recently, is that poor chemotherapy may actually slow down the natural decline of tuberculosis. To understand this we have to consider what happens to patients with tuberculosis when no chemotherapy is given. A longitudinal study conducted by the National Tuberculosis Institute in India ${ }^{11}$ has followed patients with bacillary pulmonary tuberculosis that was diagnosed but not treated. After five years $48 \%$ were dead, $18 \%$ were alive but had bacilli in their sputum (chronic bacillary excretors), and the remainder recovered spontaneously, having no bacilli in their sputum. Saving life with poor chemotherapy (such as treatment with isoniazid alone) is much easier than effecting a permanent cure. Consequently, as many tuberculosis programmes in the developing countries have had very poor treatment components (in terms both of the drugs used and of compliance), many lives were saved but more sources of infection were left in the community than would have been the case without chemotherapy. Epidemiologically therefore chemotherapy had either no effect or an adverse effect. Thus tuberculosis programmes in such countries have achieved the humanitarian end of saving lives and lessening suffering, but have failed in the public health aim of reducing the size of the problem of tuberculosis.

Another result of poor treatment in many developing countries is the emergence of bacteria that are resistant to antimicrobial drugs. Primary (initial) resistance to antituberculous drugs is common in developing countries. It is particularly bad in those countries that applied poor chemotherapy regimens relatively early, and where treatment was also given by private practitioners or could be obtained by patients from a pharmacy without consulting a physician. In many developing countries the level of initial (primary) resistance to one or more antituberculous drugs appears to be around $25 \%$ and of secondary resistance around $75 \%$. In most of these instances there is resistance to isoniazid, making regimens based on isoniazid (that is, standard chemotherapy) unlikely to be successful. These patients can be cured, however, with optimal short course chemotherapy provided that they are sensitive to rifampicin. Unfortunately, in some developing countries we are already seeing resistance to rifampicin in addition to isoniazid.

The poor results of treatment in many developing countries have had the effect that many, and in some cases most, smear positive cases of tuberculosis seen at any given time have been diagnosed and treated previously. These are obviously chronic bacillary excretors and relapses. An example of this was seen in the BCG trial area in Madras. A very careful longitudinal study was conducted for 15 years on a random sample of the trial population consisting of about 100000 people. The purpose of the study was to evaluate BCG vaccine but the investigators have incidently answered another question: what happens if the case finding is perfect but the treatment is rather poor? The case finding was indeed perfect. Every $21 / 2$ years every member of the community had a chest radiograph taken, and if something abnormal was found sputum was examined by both smear and culture. Between the "rounds" individuals with respiratory symptoms were investigated by a special chest unit. All patients had the standard treatment used in the tuberculosis programme in India, which was the responsibility of the state clinics (though the diagnosis was part of the BCG research project, financed by the central government). The position at round 5, 10 years after the beginning of the study, is shown in table 4 . Of the 778 patients who were culture positive at that time, $61 \%$ had been diagnosed as having active tuberculosis with positive sputum on a previous round $2 \frac{1}{2}$ to 10 years earlier. An additional $10 \%$ had previously been thought to have appearances of active tuberculosis on the chest radiograph but had had negative sputum at that time. ${ }^{12}$ Thus truly new disease occurred in just under $30 \%$ of cases. This is an extreme example of what happens in many countries of Asia. In the 1979 prevalence survey in China $63 \%$ of the bacteriologically confirmed cases in Beijing, Shanghai, and six provinces had received treatment in the past.

Poor treatment in many developing countries is due to very poor compliance by the patient as well as to the inadequate drug regimens. In many of these countries most of the patients given chemotherapy will fail to take a full course of treatment. This is in part caused by the poor reputation of the treatment centres and by the lack of education of the patients, so that treatment is discontinued as soon as symptoms improve, particularly if payment for drugs is required. In recent years the problem of poor compliance has been dealt with successfully by Styblo, who in the programmes assisted by the International Union Against Tuberculosis (IUAT) in Africa insists that patients are admitted to hospital for the first two months of modified short course chemotherapy, and by Kan, ${ }^{13}$ who has used fully supervised intermittent ambulatory chemotherapy successfully in Beijing, China. Although poor results of treatment may slow down the natural decline in tuberculosis, they are unlikely to reverse the downward trend in morbidity.

Table 4 Previous state of 778 bacillus positive patients seen at round 5 (Chingleput study)

\begin{tabular}{lll}
\hline Previous state & Present designations & No $(\%)$ \\
\hline $\begin{array}{l}\text { Normal chest radiograph } \\
\text { Active tuberculosis on }\end{array}$ & New cases & $228(29)$ \\
$\begin{array}{l}\text { chest radiograph } \\
\text { (suspected case) }\end{array}$ & & \\
Bacilli in sputum & Chronic cases or relapses & $47(10)$ \\
Total & & $778(100)$ \\
\hline
\end{tabular}

*Not known what treatment, if any, had been given. 


\section{HIV epidemic and tuberculosis}

HIV infection, which is widespread in many countries of Subsaharan Africa and is now threatening some countries in Asia, has already had a substantial effect and will be disastrous for the problem of tuberculosis. ${ }^{14}$

It is perhaps unfortunate that most of the studies on the impact of HIV infection on tuberculosis have come from the developed countries, particularly the United States. In these countries the risk of tuberculous infection is very low and tuberculosis is largely a residual problem of infections acquired a long time ago. In consequence, dually infected people have become a prime target of possible intervention. Although the risk of tuberculosis in people who had been infected with the tubercle bacilli before they acquired HIV infection is quite high (possibly as high as $50 \%$ ), ${ }^{14}$ the risk is probably even greater in those who are infected with HIV first. ${ }^{15}$

As the relation of HIV infection to tuberculosis will be discussed by Professor K McAdam in a future issue of Thorax I do not discuss it further here, except to say that $\mathrm{HIV}$ infection is very likely to have a disastrous impact on tuberculosis in developing countries where HIV infection is common. HIV infection is pushing the epidemiological clock back to the height of the epidemic, to the time of the first encounter of these particular populations with tubercle bacilli.

\section{The solution}

Tuberculosis in the third world is an extremely serious but soluble problem. The tools for solving the problem are available; the main ones are related to case finding (bacteriological examination of the sputum and chest radiography as a screening tool preceding bacteriology) and to treatment (potent drug regimens). Case finding is relatively easy and on the whole functions reasonably well in many developing countries. Treatment is much more difficult. It requires good organisation, which is often lacking, as well as a steady supply of effective antituberculous drugs. Many developing countries are in debt and becoming poorer; few have the financial resources and currency reserves to commit to the more expensive medication required for short course chemotherapy despite the fact that this has been shown to be more cost effective than the old "standard" chemotherapy with isoniazid, streptomycin, and thiacetazone. ${ }^{3}$ One or two developing countries have become relatively wealthy through rapid industrialisation. Korea, for instance, can now afford much more effective treatment regimens and the prevalence of tuberculosis there is rapidly falling. ${ }^{16}$ Developed countries have greatly helped the tuberculosis problem in the third world. Practically all drugs for tuberculosis were discovered in developed countries. The Medical Research Council Tuberculosis Unit in Britain under Professor Wallace Fox has made a very essential and substantial contribution by testing various drug regimens. The financial contribution of the developed countries to the problem of tuberculosis in developing countries has, however, been rather meagre.

Tuberculosis in the third world can be controlled and eventually eliminated. This demands a much larger contribution from the developed countries. A unit or units similar to the Medical Research Council Tuberculosis Unit, capable of organising therapeutic trials in developing countries, must be established.

The pharmaceutical industry must be much more active in searching for new antituberculous drugs. Although existing drugs are quite effective more powerful drugs could be developed; there is a need for new drugs suitable for shorter courses of chemotherapy than are those available at present and for the increasing number of patients in the third world who are resistant to both isoniazid and rifampicin.

Some developing countries need help in organising strong tuberculosis control programmes. WHO is considering global tuberculosis programmes. Last, but not least, there is a need for a substantially greater financial contribution by developed countries for antituberculous drugs suitable for the most effective treatment regimens. WHO estimates that 200 million dollars a year are necessary to secure medication for all the patients with active tuberculosis in the world and that at least 75 million of these will have to be given as part of international assistance. ${ }^{2}$ The spreading HIV epidemic in the third world adds great urgency to all these measures.

Respiratory Division,

STEFAN GRZYBOWSKI

University of British Columbia,

2775 Health Street,

Vancouver, British Columbia,

Canada V5Z 3J5

Reprint requests to: Professor Grzybowski

1 Kochi A. The global tuberculosis situation and the new control strategy of the World Health Organisation. Tubercle 1991;72:1-6.

2 WHO Tuberculosis Unit. First programme report (1989-1990) and future plan (1991-1995)—working document. Geneva: World Health Organisation, 1990.

3 Murray CJ, Styblo K, Rouillon A. Tuberculosis in developing countries: burden, intervention and cost. Bulletin of the International Union Against Tuberculosis and Lung Disease 1990;65:6-24.

4 Styblo K. Epidemiology of tuberculosis. Jena: Gustave Fisher, 1984

5 Nation-wide random survey for the epidemiology of pulmonary tuberculosis conducted in 1979. Chin J Respir Dis 1981;5:67-71.

6 Hong YP, Kim SJ, Kwon DW, Chang SG. Preliminary report of the sixth tuberculosis prevalence survey in Korea. In: Tuberculosis Surveillance Research Unit. Progress report. Vol 1. The Hague: TSRU, 1991:57-86.

7 Wilkinson E. Notes on the prevalence of tuberculosis in India. $R$ Soc Med Proc 1914;7:195-226.

8 Cummins SL. Tuberculosis in primitive tribes and its bearing on tuberculosis of civilized communities. Int J Publ Health 1920;1: 10-171.

9 Borrel A. Pneumonie et tuberculose chez les troupes noires. Ann Inst Pasteur 1920;34:105.

10 Grzybowski S. Tuberculosis: a look at the world situation. Chest 1983;84 756-71.

11 National Tuberculosis Institute. Tuberculosis in a rural population of South India: a five year epidemiological study. Bull WHO 1974;51:473-88.

12 Grzybowski S. Impact of chemotherapy on the epidemiology of pulmonary tuberculosis. Indian J Tuberc 1988;35:50-2.

13 Kan GQ, Zhang LX, Wu IC, Ma ZL, Liu CW, Sun FZ. Supervised intermittent chemotherapy for pulmonary tuberculosis in a rural area of China. Tubercle 1985;66:1-7.

14 Schultzer M, Fitzgerald M, Enarson D, Grzybowski S. An estimate of the future size of the tuberculosis problem in Subsaharan Africa resulting from HIV infection. Tubercle (in press).

15 Selwyn PA, Hartel D, Lewis JA, et al. A prospective study of the risk of tuberculosis among intravenous drug abusers with human immunodeficiency virus infection. $N$ Engl J Med 1989;320:545-50.

16 Di Perri G, Dazi MC, De Checchi Y, et al. Nosocomial epidemic of active tuberculosis among HIV-infected patients. Lancet 1989;ii:1502-4. 